\title{
Practice and technique of using a protective mask in older adults
}

\author{
Linda YK Lee, PhD, RN; Evangeline PW Lam, MPH, RN; Chin-Kiu Chan, \\ BN(Hons), RN; Sum-Yi Chan, BN(Hons), RN; Man-Ki Chiu, BN(Hons), RN; \\ Wing-Hei Chong, BN(Hons), RN; Kin-Wai Chu, BN(Hons), RN; Man-Sze Hon, \\ $\mathrm{BN}$ (Hons), RN; Lok-Ki Kwan, BN(Hons), RN; Kit-Lam Tsang, BN(Hons), RN; \\ Siu-Lai Tsoi, BN(Hons), RN; Chung-Wai Wu, BN(Hons), RN
}

\section{ABSTRACT}

Objective. To assess the practice and technique of using a protective mask (surgical mask) in older adults.

Methods: A convenience sample of 287 older adults aged $\geq 65$ years were recruited between January and February 2017 when there was no respiratory epidemic. Their practice and technique of using a mask were assessed using a questionnaire and an observational checklist, respectively.

Results: Older adults' practice and technique of using a mask were unsatisfactory. $30.1 \%$ and $26.9 \%$ indicated that they never wear a mask when taking care of family members with fever and respiratory infection, respectively. None could correctly perform all 12 steps in wearing and taking off a mask. 92.3\%, 96.6\%, and 93.7\% did not perform hand hygiene before wearing and taking off the mask and after disposing of the mask, respectively.

Conclusion: Compliance of older adults with wearing masks during a non-epidemic period was low. The commonly omitted steps of wearing and taking off a mask were related to hand hygiene. We recommend using the knowledge-attitude-practice model to rectify misconceptions and strengthen awareness on the use of masks in the required situations and on commonly omitted or incorrectly performed techniques.

Key words: Aged; Masks; Public health; Respiratory tract infections

\author{
School of Nursing and Health Studies, \\ The Open University of Hong Kong, Hong \\ Kong
}

Correspondence to: Linda Yin-King Lee, School of Nursing and Health Studies, The Open University of Hong Kong, Hong Kong. Email:yklee@ouhk.edu.hk

\section{INTRODUCTION}

Older adults generally are more susceptible to infections, especially those with weakened immune function or multiple comorbidities. ${ }^{1}$ Respiratory tract infection is a major cause of death among older adults. ${ }^{2}$ Preventive behaviour is effective in limiting the spread of infectious diseases. ${ }^{3}$ To protect older adults from respiratory infections, the use of masks such as surgical masks is recommended. ${ }^{4}$ A mask can block potentially infectious droplets. When used correctly, masks are effective in protecting oneself and preventing others from acquiring respiratory infections. ${ }^{5-7}$ However, incorrect use may hinder its effectiveness.

Studies have reported high compliance of adults with wearing masks when visiting clinics or hospitals during influenza season or a pandemic to protect oneself $(81.9 \%)$ and others $(91.8 \%)^{5}$ and when having respiratory symptoms during respiratory epidemics ( $88.7 \%$ to $92.4 \%$ ). ${ }^{8,9}$ During the COVID-19 pandemic, compliance with wearing masks is high in adults ${ }^{10}$ and older adults. ${ }^{11}$ In Hong Kong, $>90 \%$ of older adults use a mask frequently in public or in clinics. ${ }^{11}$ However, it is less common to wear a mask 
in many western countries. ${ }^{12}$ The differences in public health policy and public interest may attribute to the discrepancy. Compliance with wearing masks during a non-epidemic period has not been investigated systematically. ${ }^{13}$ Compliance may be high because of a habit developed during the epidemic or may be low because of immediate behavioural change in the epidemic. ${ }^{14}$ Wearing and taking off a mask involves 12 steps, ${ }^{6}$ but $52 \%$ of outpatients and their caregivers correctly identify three steps only. ${ }^{5}$

Being female is reported to be a determinant of using a mask to protect against respiratory infections, ${ }^{4,8,15}$ but no gender difference is reported in other studies. ${ }^{16,17}$ This study aimed to assess the practice and technique of using a mask in older adults.

\section{METHODS}

This cross-sectional study was approved by the Research Ethics Committee of The Open University of Hong Kong (reference: 2016-06). A convenience sample of 287 older adults aged $\geq 65$ years who had no allergy to masks and alcohol hand rub were recruited in public areas in Hong Kong between January and February 2017 when there was no respiratory epidemic.

Although a mask-use scale that assesses the practice of wearing a mask such as the location of use and whether the mask is used to protect oneself or others has been developed ${ }^{5}$ and validated ${ }^{18}$ in Hong Kong, the present study conceptualised the practice of wearing a mask in terms of required situations. ${ }^{6}$ Thus, we developed a new questionnaire based on the guidelines in Use Mask Properly. ${ }^{6}$ It comprises three statements of situations that require wearing a mask in a non-epidemic period, each was rated on a five-point Likert scale in terms of frequency from 1 (never), 2 (seldom), 3 (sometimes), 4 (often), to 5 (always). An option of 'not applicable' was provided. Responses to each required situation were analysed separately. This questionnaire demonstrated high content validity index (1.0) and test-retest reliability coefficient (0.83). ${ }^{19}$

The observational checklist comprises eight steps of wearing and four steps of taking off an earlooptype surgical mask. Each is rated as 0 (incorrect) or 1 (correct) by a single researcher. The total score ranges from 0 to 12; higher scores indicate a better technique. This checklist demonstrated high content validity index (1.0) and high inter-rater agreement (kappa coefficient $=0.92) .{ }^{20}$

Mann-Whitney $U$ test was used to test sex differences in each situation. Independent $t$-test was used to test sex differences in the technique of wearing and taking off a mask. The level of statistical significance was 0.05 .

\section{RESULTS}

287 older people ( 169 women and 118 men) aged 65 to 74 years $(n=145)$ or 75 to 84 years $(n=142)$ were included. Their practice and technique of using a mask was unsatisfactory. $30.1 \%$ and $26.9 \%$ indicated that they never wear a mask when taking care of family members with fever and respiratory infection, respectively (TABLE $\mathbf{I})$. Women wore a mask more frequently than men $(p<0.05)$.

The mean score for technique was $5.3 \pm 1.8$ (range, $1-10)$. None could correctly perform all 12 steps in wearing and taking off a mask. $94.1 \%$ could position the elastic band properly and $87.1 \%$ could ensure that the part with the metallic strip is on the upper side. $92.3 \%, 96.6 \%$, and $93.7 \%$ did not perform hand hygiene before wearing and taking off the mask and after disposing of the mask, respectively (TABLE 2).

\section{DISCUSSION}

In Hong Kong, compliance with wearing masks during respiratory epidemics is high (88.7\%92.4\%). 8,9,11,21 However, during a non-epidemic period, the compliance among older adults was low (27.8\%-40.5\%), which is consistent with $14.7 \%$ to $48.1 \%$ reported in a study. ${ }^{13}$ People are less likely to maintain high compliance during a non-epidemic period because their good performance in the epidemic is due to immediate behavioural change. ${ }^{14}$ The Health Belief Model states that perceived susceptibility is one of the variables determining the update of a health preventive behaviour. ${ }^{4}$ The previously established good practice in the population cannot be sustained.

People tend to assume that they know how to wear a mask. ${ }^{5}$ In the present study, older adults did not demonstrate proper technique of wearing and taking off a mask. The commonly omitted steps 
TABLE 1

Practice of wearing masks among older adults $(n=287)$

\begin{tabular}{|c|c|c|c|c|c|c|}
\hline Required situation & Always* & Often ${ }^{*}$ & Sometimes* & Seldom* & Never ${ }^{*}$ & $\begin{array}{c}\text { Not } \\
\text { applicable* }\end{array}$ \\
\hline When taking care of family members with fever & $70(27.8)$ & $32(12.7)$ & $34(13.5)$ & $40(15.9)$ & $76(30.1)$ & 35 \\
\hline $\begin{array}{l}\text { When taking care of family members with } \\
\text { respiratory infection }\end{array}$ & $79(31.2)$ & $24(9.5)$ & $37(14.6)$ & $45(17.8)$ & $68(26.9)$ & 34 \\
\hline When having respiratory symptoms & $113(40.5)$ & $37(13.3)$ & $36(12.9)$ & $54(19.3)$ & $39(14.0)$ & 8 \\
\hline
\end{tabular}

* Data are presented as No. (\%) of older adults

TABLE 2

Technique of wearing and taking off a mask among older adults $(n=287)$

\begin{tabular}{lcc}
\hline Technique & Correct $^{\star}$ & Incorrect $^{*}$ \\
\hline Wearing a mask & & \\
Perform hand hygiene before wearing the mask. & $22(2.7)$ & $265(92.3)$ \\
Choose the appropriate size of mask. & $193(67.2)$ & $94(32.8)$ \\
Ensure the colored side of the mask is facing outwards. & $217(75.6)$ & $70(24.4)$ \\
Ensure the part with metallic strip is on the upper side. & $250(87.1)$ & $37(12.9)$ \\
Position the elastic band properly. & $270(94.1)$ & $17(5.9)$ \\
Press firmly on the metallic strip to the bridge of nose and face. & $106(36.2)$ & $183(63.8)$ \\
Extend the mask to cover mouth, nose and chin. & $216(75.3)$ & $71(24.7)$ \\
Avoid touching the mask once it is secured. & $98(34.1)$ & $189(65.8)$ \\
Taking off a mask & & $278(96.6)$ \\
Perform hand hygiene before taking off the mask. & $97(3.1)$ & $240(83.6)$ \\
Touch only the elastic bands. & $86(30.0)$ & $302(70.0)$ \\
Dispose of the used mask in a lidded rubbish bin. & $18(6.3)$ & $269(93.7)$ \\
\hline
\end{tabular}

* Data are presented as No. (\%) of older adults

were related to hand hygiene. These are essential to prevent acquiring respiratory pathogens through touch. Wearing a mask and performing hand hygiene together are recommended to prevent transmission of influenza in community settings. ${ }^{22,23}$ According to the knowledge-attitude-practice model, increasing knowledge and attitude influences change of practice. ${ }^{24}$ It is suggested to rectify misconceptions and strengthen awareness on the use of masks in the required situations and on commonly omitted or incorrectly performed techniques.

There are limitations to the present study. Although direct observation is better than selfreporting in terms of assessing performance, it is impossible to eliminate the Hawthorne effect. Moreover, a question asks whether the subjects wear a mask when they are taking care of family members with fever. Because some fever cases are noninfectious, the measurement might be overestimated. Further studies to determine predictors of proper mask usage (such as educational background, socioeconomic background, history of having prior severe respiratory conditions, and supply and availability of masks) are warranted.

\section{CONCLUSION}

Compliance of older adults with using masks during a non-epidemic period was low. The commonly omitted steps of wearing and taking off a mask were related to hand hygiene. We recommend using the knowledge-attitude-practice model to rectify misconceptions and strengthen awareness on the use of masks in the required situations and on commonly omitted or incorrectly performed techniques. 


\section{FUNDING}

This research received no specific grant from any funding agency in the public, commercial, or notfor-profit sectors.

\section{DECLARATION}

All authors have no conflicts of interest to disclose. A study with a large sample has been published in: Lee LY, Lam EP, Chan CK, et al. Practice and technique of using face mask amongst adults in the community: a cross-sectional descriptive study. BMC Public Health 2020;20:948.

\section{REFERENCES}

1. Chasqueira MJ, Paixão $P$, Rodrigues $M L$, et al. Respiratory infections in elderly people: viral role in a resident population of elderly care centers in Lisbon, winter 2013-2014. Int J Infect Dis 2018:69:1-7. Crossref

2. Geffen L. Common upper respiratory tract problems in the elderly: a guide to clinical diagnosis and prudent prescription. S Afr Fam Pract 2006;48:20-23. Crossref

3. Berrigan D, Dodd K, Troiano RP, Krebs-Smith SM, Barbash RB. Patterns of health behavior in US adults. Prev Med 2003;36:61523. crossref

4. Tang CS, Wong CY. Factors influencing the wearing of facemasks to prevent the severe acute respiratory syndrome among adult Chinese in Hong Kong. Prev Med 2004;39:1187-93. Crossref

5. Ho HS. Use of face masks in a primary care outpatient setting in Hong Kong: knowledge, attitudes and practices. Public Health 2012;126:1001-6. Crossref

6. Centre for Health Protection. Use Mask Properly: Protect Ourselves and Protect Others. https://www.chp.gov.hk/files/her/ use_mask_properly_pamphlet.pdf. Accessed 5 April 2019.

7. World Health Organization. Practical Guidelines for Infection Control in Health Care Facilities. http://www.wpro.who.int/ publications/docs/practical_guidelines_infection_control.pdf. Accessed 5 April 2019.

8. Lau JT, Griffiths S, Choi KC, Lin C. Prevalence of preventive behaviors and associated factors during early phase of the H1N1 influenza epidemic. Am J Infect Control 2010;38:374-80. Crossref

9. Lau JT, Kim JH, Tsui HY, Griffiths S. Anticipated and current preventive behaviors in response to an anticipated human-tohuman H5N1 epidemic in the Hong Kong Chinese general population. BMC Infect Dis 2007;7:18. Crossref
10. Cowling BJ, Ali ST, Ng TWY, et al. Impact assessment of nonpharmaceutical interventions against coronavirus disease 2019 and influenza in Hong Kong: an observational study. Lancet Public Health 2020;5:e279-e288. Crossref

11. Kwan RY, Lee PH, Cheung DS, Lam SC. Face mask wearing behaviors, depressive symptoms, and health beliefs among older people during the COVID-19 pandemic. Front Med 2021;8:590936. Crossref

12. Wong $\mathrm{SH}$, Teoh JYC, Leung $\mathrm{CH}$, et al. COVID-19 and public interest in face mask use. Am J Respir Crit Care Med 2020;202:4535. Crossref

13. Lee LY, Lam EP, Chan CK, et al. Practice and technique of using face mask amongst adults in the community: a cross-sectional descriptive study. BMC Public Health 2020;20:948. Crossref

14. Lau JT, Tsui H, Kim JH, Griffiths S. Perceptions about status and modes of H5N1 transmission and associations with immediate behavioral responses in the Hong Kong general population. Prev Med 2006;43:406-10. Crossref

15. Bish A, Michie S. Demographic and attitudinal determinants of protective behaviours during a pandemic: a review. Br J Health Psychol 2010;15:797-824. Crossref

16. Taylor M, Raphael B, Barr M, Agho K, Stevens G, Jorm L. Public health measures during an anticipated influenza pandemic: factors influencing willingness to comply. Risk Manag Healthc Policy 2009;2:9-20. Crossref

17. Kuo PC, Huang JH, Liu MD. Avian influenza risk perception and preventive behavior among traditional market workers and shoppers in Taiwan: practical implications for prevention. PLoS One 2011;6:e24157. Crossref

18. Lam SC, Chong CYA, Chung JYS, Lam MY. Methodological study on the evaluation of face mask use scale among public adult: cross-language and psychometric testing. Korean J Adult Nurs 2020;32:46-56. Crossref

19. Polit DF, Beck CT. The content validity index: are you sure you know what's being reported? Critique and recommendations. Res Nurs Health 2006;29:489-97. Crossref

20. Nieswiadomy RM. Foundations of Nursing Research. 6th edition. Boston: Pearson; 2012.

21. Bressington DT, Cheung TCC, Lam SC, et al. Association between depression, health beliefs, and face mask use during the COVID-19 pandemic. Front Psychiatry 2020;11:571179. Crossref

22. Aiello AE, PerezV, Coulborn RM, Davis BM, Uddin M, Monto AS. Facemasks, hand hygiene, and influenza among young adults: a randomized intervention trial. PLoS One 2012;7:e29744. Crossref

23. Suess $\mathrm{T}$, Remschmidt C, Schink SB, et al. The role of facemasks and hand hygiene in the prevention of influenza transmission in households: results from a cluster randomised trial; Berlin, Germany, 2009-2011. BMC Infect Dis 2012;12:26. Crossref

24. Rahbar T, Garg S, Tripathi R, Gupta VK, Singh MM. Knowledge, attitude, behavior and practice (KABP) regarding HIV/AIDS among pregnant women attending PPTCT programme in New Delhi. J Commun Dis 2007;39:179-84. 